\title{
INFLATION AND MONETARY POLICY IN JANUARY 2014
}

\author{
A.Bozhechkova
}

The consumer price index stood at 0.6\% in January 2014 (1.0\% in January 2013), rising 0.1 p.p. above the value recorded in December 2013. Inflation reached 6.1\% at the end of 12 months. The consumer price index stood at $0.5 \%$ within the first 17 days in February 2014. Net capital outflow from the country reached \$16,6bn in Q4 2013 to a total of $\$ 64,7 \mathrm{bn}$, reaching a total of $\$ 64,7 \mathrm{bn}$ within 12 months.

In January 2014, inflation in the Russian Federation remained at a high level: the consumer price index stood at $0.6 \%$ at the month's end (as compared to $0.5 \%$ in December 2013), by 0.4 p.p. below the level recorded in 2013. As a result, inflation reached $6.1 \%$ on an annualized basis (Fig. 1). Core inflation ${ }^{1}$ stood at $0.4 \%$ in January 2014 , by 0.1 p.p. lower than the level recorded in 2013.

Prices of food products increased $1.0 \%$ in January 2014 against December 2013 (Fig. 2). Prices of the following food products slowed down: butter (from 2.3\% in December 2013 to 1.3\% in January 2014), milk and dairy products (from 1.6\% in December 2013 to $1.1 \%$ in January 2014), fish and seafood (from $1.5 \%$ in December 2013 to $0.8 \%$ in January 2014). Prices of the following food products kept falling: eggs (-6\% in January 2014 against $-0.6 \%$ in December 2013), cereal and bean products (-0.3\% December 2013 and January 2014$)$, granulated sugar (-0.8\% against $-1.4 \%$ in December 2013$)$, sunflower oil (-0.7\% against $-1.1 \%$ in December 2013), red meat and poultry (-0.1\% in December 2013 and in January 2014). Prices of the following food products saw increased growth rates: fruits and vegetable products (from 2.8\% in December 2013 to $5.8 \%$ in January 2014), alcoholic beverages (from $0.4 \%$ in December 2013 to $1.6 \%$ in January 2014).

Prices and tariffs of retail paid services in January 2014 increased 0.5\%, whereas in December 2013 they increased $0.6 \%$. In January 2014, tariffs of housing and public utility services grew at a rate of $0.2 \%$, showing a 0.1 p.p. growth over the level recorded in December 2013. Prices of the following services saw increased growth rates: international travel services (from 0.1\% in December 2013 to $0.4 \%$ in January 2014), medical services (from 0.6\% in December 2013 to 1.4\% in January 2014), culture organizations' services (from 1.5\% in December 2013 to $1.6 \%$ in January 2014),

1 The reference consumer price index is an indicator which describes the level of inflation in the consumer market, net of seasonal factors (prices of fruit and vegetable products) and administrative factors (tariffs of regulated types of service, etc.). The index is also calculated by the Federal State Statistic Service of Russia (Rosstat). personal services (from 0.5\% in December 2013 to $0.7 \%$ in January 2014), insurance services (from $0.3 \%$ in December 2013 to $1.0 \%$ in January 2014), education services (from $0.0 \%$ in December 2013 to $0.2 \%$ in January 2014). Prices of the following services slowed down: passenger transport services (from 3.4\% in December 2013 to $0.1 \%$ in January 2014).

In January 2014, growth rate of prices of non-food products increased 0.1 p.p. against December 2013 and stood at $0.3 \%$. Prices of the following non-food products increased most: tobacco products by $0.8 \%$, the same growth grate was recorded in December 2013; washing and cleaning products by $0.7 \%$

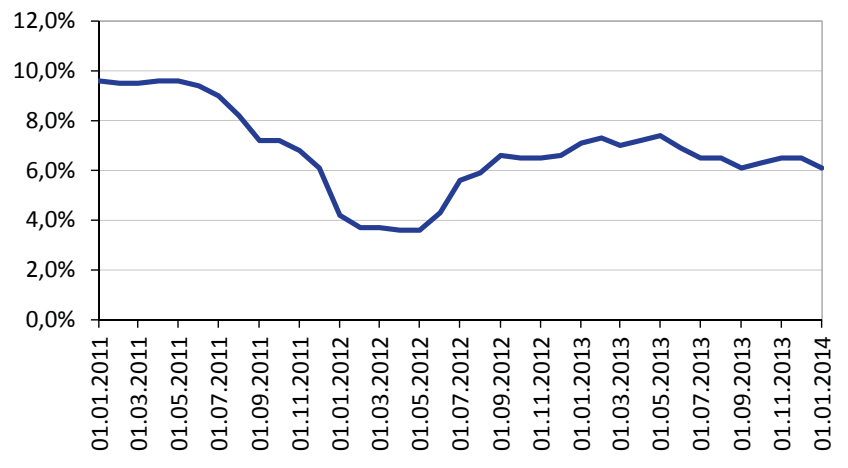

Source: the Federal State Statistic Service of Russia (Rosstat). Fig. 1. CPI growth rate in 2011 thru 2013 (\% year over year)

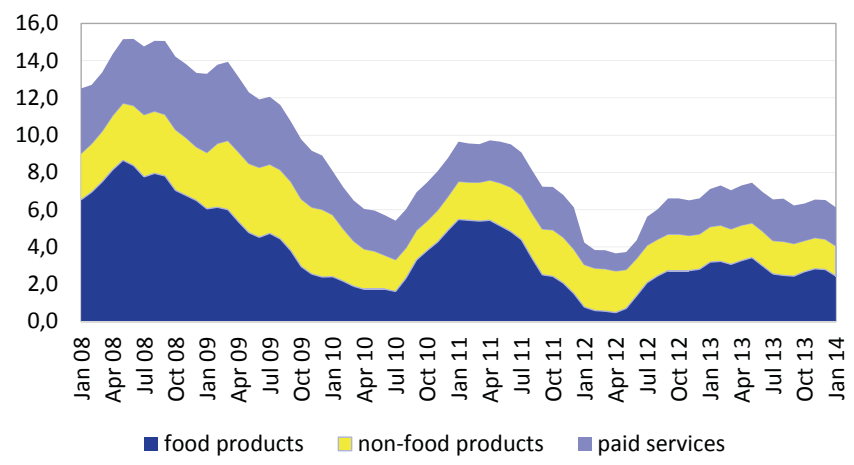

Source: the Federal State Statistic Service of Russia (Rosstat).

Fig. 2. Inflation factors in 2008 thru 2014 (\%, month to the corresponding month of the previous year) 
(+0.4\% in December 2013), consumer electronics and other household appliances by $0.5 \%$ (+0.3\% in December 2013$)$, audio-video appliances by $0.4 \%(+0.2 \%$ in December 2013). Prices of the following non-food products slowed down: clothing and underwear by $0.2 \%(+0.4 \%$ in December 2013), knitwear by $0.3 \%$ $(+0.5 \%$ in December 2013), footwear by $0.1 \%(+0.2 \%$ in December 2013). Prices of motor gasoline increased $0.2 \%$ (-0.5\% in December 2013).

In February 2014, inflation kept growing basically through growth in the price of fruits and vegetables and dairy products. Note that weakening of the ruble made a certain contribution in pushing up inflation, factoring in a big share of imported goods in the consumption of economic agents in the Russian Federation. The already happened devaluation of the ruble may accelerate inflation by $0.3-0.5$ p.p. in the short run. Furthermore, if the ruble keeps weakening within a horizon of 6-12 months, the effect of the ruble exchange rate on prices may reach $50 \%$, i.e. price growth may accelerate at half a rate the ruble weakens against the US dollar. Within 24 days in February 2014 the consumer price index stood at $0.7 \%(0.5 \%$ in the corresponding period of 2013). Lack of pronounced demand-driven pressure on prices as well as improved situation in the global agricultural market is the key factor constraining inflation.

In January 2014, the monetary base (broad definition) contracted $11 \%$ to $\mathrm{Rb} 9351,2$ bn (Fig. 3). The following components of the monetary base (broad definition) saw a decline: banks' correspondent accounts (a decline of $10.1 \%$ to $\mathrm{Rb} 1142 \mathrm{bn}$ against December 2013), bank deposits (a decline of $75.7 \%$ to $\mathrm{Rb} 126 \mathrm{bn})$, the volume of cash in circulation, including cash on hand at credit institutions slid down by $7.6 \%$ to $\mathrm{Rb} 7672 \mathrm{bn}$. The volume of obligatory reserves increased $0.6 \%$ to reach $\mathrm{Rb} 411,3 \mathrm{bn}$.

In January 2014, the monetary base (narrow definition) (cash plus obligatory reserves) contracted 7.3\% to reach $\mathrm{Rb} 8083,4 \mathrm{bn}$ (Fig. 4).

In January 2014, volume of excessive reserves at commercial banks ${ }^{1}$ shrank $29.1 \%$ to $\mathrm{Rb} 1268 \mathrm{bn}$ while bank's debt on repo transactions was reduced 5.5\% to $\mathrm{Rb} 2,7$ trillion. According to the data on February 25,2014 , banks' debt on repo transactions was reduced to $\mathrm{Rb} 2,3$ trillion. The interest rate in the interbank lending market ${ }^{2}$ was maintained at an average of $6.1 \%$ in January 2014 (6.4\% in December 2013), 13\%

1 Commercial banks' excess reserves with the Central Bank are referred to the amount of commercial banks' correspondent accounts, their deposits with the Central Bank, as well as Central Bank bonds held by commercial banks.

2 Interbank interest rate is the monthly average MIACR, an interest rate on ruble overnight interbank loans.

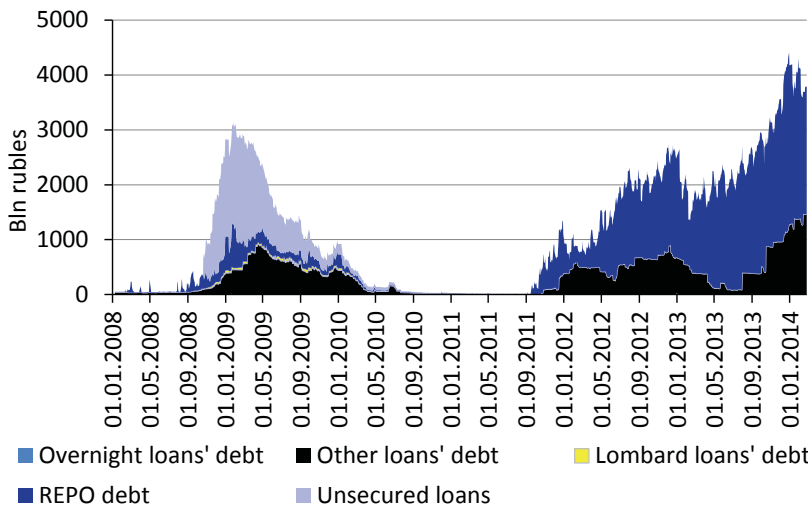

Fig. 3. Commercial banks' debt owed to the Bank of Russia in 2008 thru 2014

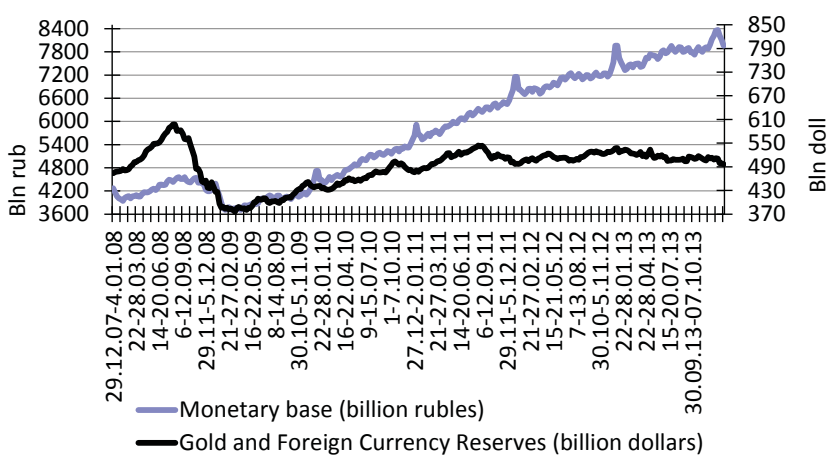

Fig. 4. Dynamics of the monetary base (narrow definition) and gold and foreign currency (international) reserves of the Russian Federation in 2007 thru 2014

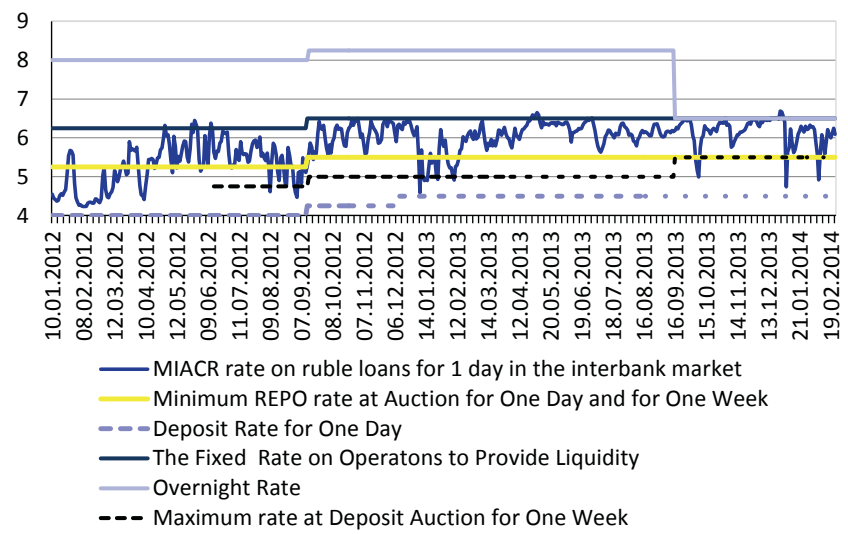

Fig. 5. Bank of Russia's interest rates corridor and dynamics of the interbank lending market in 2012 thru 2014 (\% p.a.)

higher than the level recorded in January 2014 (5.4\% in January 2013). In the period of February 1 thru 24, 2014 the rate averaged $5.92 \%$ (Fig. 5).

On January 13, 2014, the Central Bank provided Russian banks with $\mathrm{Rb} 480 \mathrm{bn}$ out of a limit of $\mathrm{Rb} 500 \mathrm{bn}$ as part of a 3-month repo auction secured by non-market assets. The hurdle rate was $5.76 \%$ with a lowest rate of $5.75 \%$. As a reminder, it was October 15, 2013 when 
the regulator held such auction for the first time. The amount of allocated funds totaled $\mathrm{Rb} 500 \mathrm{bn}$ at $5.76 \%$ p.a.. During a similar auction which was held by the Bank of Russia on February 10, 2014 the hurdle rate stood at $5.85 \%$ while the allocated amount totaled $\mathrm{Rb} 200 \mathrm{bn}$. It should be noted that it is only large banks with a distinctly bigger collateral base that can afford such actions despite fairly easy terms of lending at a floating interest rate.

The Central Bank's international reserves totaled $\$ 498,9$ bn as of February 1, 2014, showing a 2.1\% contraction since the beginning of the year (Fig. 4). At the same time, the monetary gold reserves increased $\$ 1,7 \mathrm{bn}$ in January 2014 after a positive revaluation of assets. In general, the contraction of the international reserves in January 2014 was basically caused by the regulator's foreign currency interventions.

Bank of Russia's foreign currency interventions through selling foreign exchange amounted to $\$ 7817 \mathrm{~m}$ and $586 \mathrm{~m}$ euro by the end of January 2014, making a record since the fall of 2011, when the amount of foreign exchange sold by the regulator in the domestic market reached \$1,17bn (Fig. 6). Factoring in a substantial amount of foreign exchange interventions, the Bank of Russia's measures are aimed at not only flattening volatility of the ruble exchange rate, but also maintaining it amid ongoing weakening of national currencies in developing countries. In January 2014, the regulator conducted no operations to purchase foreign currencies in connection with the Federal Treasury replenishing or spending foreign currency resources of sovereign funds. The 14-time 5-kopek extension of the borders of the dual-currency trading band in January 2014 pushed them to a level of $\mathrm{Rb} 34,25-41,25$. In the period of February 1 thru 24, 2014, the regulator repeatedly made a 5-kopek shift on the dual-currency trading band. As of February 24, 2014, the dual-currency trading band was kept with a range of $\mathrm{Rb} 35,05-$ 42,05. In the period of February 1 thru 24, 2014, Bank of Russia's foreign currency sales volumes amounted to $\$ 5086 \mathrm{~m}$, and foreign currency interventions associated with the Federal Treasury replenishing or spending foreign currency resources of sovereign funds totaled $\$ 295 \mathrm{~m}$. Steady weakening of the ruble exchange rate, in our opinion, raises economic agents' devaluation expectations, thereby weakening further the ruble exchange rate and spending the Central Bank of Russia's reserves. In our opinion, drastic devaluation of the ruble exchange rate with its subsequent stabilization at a level reached would be a better policy.

According to the Bank of Russia's preliminary estimates, net capital outflow from the country reached $\$ 16,6 \mathrm{bn}$ in Q4 2013, making a total of $\$ 64,7 \mathrm{bn}$ within 12 months, by $\$ 10,1 \mathrm{bn}$ more than the amount record-

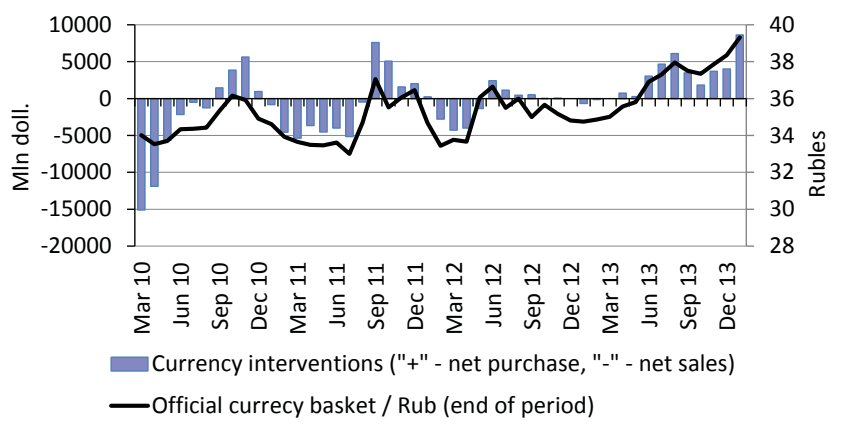

Fig. 6. Bank of Russia's currency interventions and ruble exchange rate vs. the currency basket in March 2010 thru January 2014

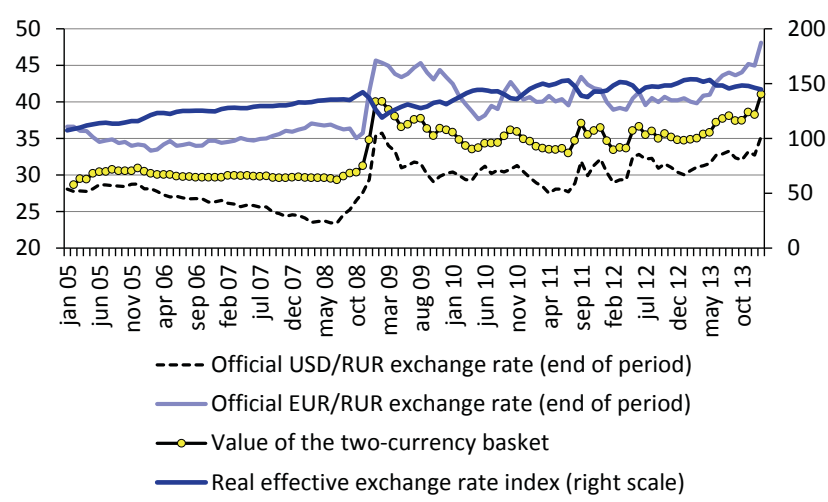

Fig. 7. Ruble exchange rate indicators in January 2005 thru January 2014

ed within 12 months in 2012. Banks' and other sectors' net capital export reached $\$ 5,2 \mathrm{bn}$ and $\$ 59,7 \mathrm{bn}$ respectively in the period of January 2013 thru December 2013.

In January 2014, the real effective ruble exchange rate vs. foreign currencies weakened by $1 \%(-1.1 \%$ in December 2013). As a reminder, the real effective ruble exchange rate lost 2\% in 2013 in general (Fig. 7).

In January 2014, the ruble-to-dollar exchange rate dropped from $7.9 \%$ to $\mathrm{Rb} 35,2$. The ruble weakened against euro by $6.7 \%$ ( $R b 48,1$ ) while the euro-to-dollar exchange rate averaged 1.36 during the same month. The value of the dual currency basket dropped $7.3 \%$ to $\mathrm{Rb} 41,0$ in January 2014. Within 26 days in February 2014 the ruble-to-dollar exchange rate dropped $1.1 \%$ to reach $\mathrm{Rb} 35,6$ per US dollar while the euro-to-ruble exchange rate fell $2.6 \%$ to reach $\mathrm{Rb} 48,9$ per euro, so the value of the dual currency basket lost $1.9 \%$ to $\mathrm{Rb} 41,6$. The euroto-dollar exchange rate was 1.36 in February 2014. The ruble lost vs. the US dollar basically because of a trend towards decline in the current account balance and capital fleeing the country. Note that the Euro strengthened in response to the Euro-zone recovering from recession.

The Bank of Russia Board of Directors made a decision on January 13, 2014 to cut the volume of targeted 
interventions from $\$ 60 \mathrm{~m}$ to 0 daily. This measure of the Central Bank of Russia is aimed at further enhancing flexibility of the exchange rate formation mechanism, creating conditions so that economic agents can gradually adapt to fluctuations of the exchange rate and master currency risk management instruments.

On February 3, 2014, the regulator introduced "fine tuning" operations on liquidity provision due to the abolishment of daily repo overnight auctions. The intensity of using "fine tuning" operations by the Bank of Russia is planned to be reduced to 2-3 times monthly as the banking system adapts to the use of the key instruments of liquidity provision and absorption of the Central Bank of Russia for longer periods (from 1 week to 1 year).
On February 17, 2014, the Bank of Russia supplemented its monetary policy system with "fine tuning" operations aimed at absorbing liquidity. Such operations will be conducted as 1-6-day deposit auctions at a maximum rate equal to the key rate (5.5\%).

According to the Bank of Russia, "fine tuning" deposit operations are aimed at absorbing excessive liquidity in the banking sector at moments when the supply of liquid assets outstrips largely the demand due to autonomous factors. The introduction of "fine tuning" instruments will allow liquid assets to be managed more efficiently, which will eventually create preconditions for flattening interest rates volatility in the interbank lending market. 